\title{
A guerra no prato: uma breve análise sobre o problema de abastecimento de carne verde no Rio Grande do Sul, durante a Segunda Guerra Mundial
}

\author{
The war on the plate: a brief analysis of problem of meat supplies in Rio \\ Grande do Sul during Second World War
}

\section{Tamires Xavier Soares *}

Resumo: A Era Vargas, ao longo dos anos, tem se mostrado um período bastante importante para se pesquisar a história do movimento operário e a legislação trabalhista brasileira, porém, não se pode olhar para esse período sem considerar a conjuntura externa. No período de 1939 a 1945, eclodiu a Segunda Guerra Mundial. O Brasil se manteve neutro até 1942, contudo, os reflexos desse conflito foram sentidos pelos brasileiros desde os primeiros momentos. A escassez de gêneros de primeira necessidade passou a fazer parte do cotidiano da população. A carne verde, base da alimentação da classe trabalhadora, sofreu majoração de preços; por outro lado, essa foi uma oportunidade para os criadores de gado e para os donos de frigoríficos. Desse modo, o objetivo, neste artigo, é analisar de que forma esse novo contexto foi administrado pelo governo e pelos trabalhadores. Para isso, serão utilizados um processo da Justiça do Trabalho de Porto Alegre e notícias do jornal Correio do Povo.

Palavras-chave: Segunda Guerra Mundial; carne; economia.

\begin{abstract}
The Vargas Era, over the years, has proved to be a very important period to research the history of the labor movement and Brazilian labor legislation, but one cannot look at this period without considering the external conjuncture. From 1939 to 1945, the outbreak of the Second World War, Brazil remained neutral until 1942, but the reflections of this conflict were felt by Brazilians from the first moments. The lack of basic necessities became part of the daily life of the population. Beef, the staple of working-class food, has been increased in price; On the other hand, this was an opportunity for cattle ranchers and refrigerator owners. Thus, the objective in this article is to analyze how this new context was administered by the government and the workers. For this, we will use a process of Labor Justice of Porto Alegre and news from the newspaper Correio do Povo.
\end{abstract}

Keywords: Second World War; meat; economy.

Doutoranda em História na Universidade Federal de Santa Maria (UFSM). Mestre em História pela Pontifícia Universidade Católica do Rio Grande do Sul (PUC-RS). Graduada em História pela Universidade Federal de Pelotas (UFPel). E-mail: tamiresxavier@outlook.com. ORCID: https://orcid.org/0000-0002-4087-6483. 
Getúlio Vargas governou o Brasil por mais de 18 anos, assumindo, primeiramente, a cadeira de presidência como provisório, depois foi eleito indiretamente pela Câmara dos Deputados, deu um golpe de estado em 1937, tornando-se um ditador e, por fim, voltou ao poder eleito pelo povo em 1951. O período entre 1930 a 1937, foi muito explorado pelos especialistas, tendo em vista a grande mobilização da classe trabalhadora, porém, o chamado Estado Novo (19371945), implantado a partir de uma mentira de ameaça comunista, foi considerado, por muitos anos, um momento de desmobilização da luta de classe. Nos últimos 15 anos, pesquisadores estão fazendo novas descobertas, as quais contradizem essa visão de submissão do movimento operário ao governo varguista. ${ }^{1}$

Outro elemento histórico que, nos últimos anos, está sendo problematizado é o reflexo da Segunda Guerra Mundial (1939 a 1945) no Brasil, sendo esse um conflito de grandes proporções, o qual não pode ser relegado. ${ }^{2}$ Ao se considerar que o país dependia de relações comerciais com os países beligerantes, que boa parte dos produtos manufaturados eram importados do Velho Continente e que, por sua vez, esses consumiam boa parte da nossa produção agropastoril, entende-se que se deve olhar com mais atenção para o referido momento.

Como exemplo desses trabalhos, podemos citar: SILVA, Fernando Teixeira da. A carga e a culpa: os operários das docas de Santos, direitos e cultura de solidariedade, 1937-1968. Dissertação (Mestrado em História) - Instituto de Filosofia e Ciências Humanas, Universidade Estadual de Campinas, Campinas, 1992; FORTES, Alexandre. Revendo a legislação dos sindicatos: metalúrgicos de Porto Alegre (1931-1945). In: FORTES, Alexandre et al. Na luta por direitos. Estudos recentes em história social do trabalho. Campinas: Editora da Unicamp, 1999; COSTA. Hélio. Em busca da memória: comissão de fábrica, partido e sindicalismo no pós-guerra. São Paulo: Scritta, 1995; KONRAD, Glaucia. Os trabalhadores e o Estado Novo no Rio Grande do Sul: um retrato da sociedade e do mundo do trabalho (1937-1945). Tese (Doutorado em História) - Instituto de Filosofia e Ciências Humanas, Universidade Estadual de Campinas, Campinas, 2006; PAOLI, Maria Célia. Os trabalhadores urbanos na fala dos outros. Tempo, espaço e classe na história operária brasileira. In: LOPES, José S. L. Cultura \& Identidade Operária: aspectos da cultura da classe trabalhadora. Rio de Janeiro: PROED; Marco Zero; Museu Nacional, 1987; SPERANZA, Clarice Gontarski. Cavando direitos: as leis trabalhistas e os conflitos entre os mineiros de carvão e seus patrões no Rio Grande do Sul (1940-1950). São Leopoldo-RS: Oikos, 2014.

2 FORTES, Alexandre. Os impactos da Segunda Guerra Mundial e a regulação das relações de trabalho no Brasil. Nuevos Mundos, 2014; FERREIRA, Jorge. Brasil, 1942 estado e sociedade contra o reich. Acervo, Rio de Janeiro, v. 30, n. 2, p. 89-109, jul./dez. 2017 SECRETO, María Verónica. Soldados da borracha: trabalhadores entre o sertão e a Amazônia no governo Vargas. São Paulo: Fundação Perseu Abramo, 2007; LIRA, Clarice. 0 Piauí em tempos de Segunda Guerra: mobilização local e as experiências do contingente piauiense da FEB. Jundiaí, SP: Paco, 2017; ALCANTARA, Patrícia. Os conflitos de um conflito: processos trabalhistas ajuizados nas Juntas de Conciliação e Julgamento de Belo Horizonte durante a Segunda Guerra Mundial (1939-1945). 2018. 155 f. (Dissertação) Mestrado em História- Instituto de Ciências Humanas e Sociais - Instituto Multidisciplinar, Universidade Federal Rural do Rio de Janeiro, Seropédica, Rio de Janeiro, 2018. 
Embora a Segunda Guerra Mundial tinha sido deflagrada em 1939, o Brasil se manteve neutro até 1942, quando submarinos alemães torpedearam navios brasileiros, levando-os ao naufrágio, em agosto desse mesmo ano. A partir de então, Vargas declarou guerra e aproximou-se do grupo Aliado. ${ }^{3}$ Os reflexos desse conflito foram sentidos pelos brasileiros desde o início, pois diversos produtos consumidos pelos trabalhadores, em seu cotidiano, passaram a ficar escassos e a sofrer majoração de valor. Entre esses, é possível citar a carne, o açúcar branco, o pão branco, o combustível e o leite.

A partir da declaração de guerra, em 1942, os efeitos se intensificaram, uma vez que o governo federal passou a mobilizar esforços para formação do front interno e externo. Nesse contexto, 25 mil brasileiros foram enviados para o palco de batalha na Europa, porém, os que ficaram deviam cooperar, produzindo o máximo e abdicando de direitos conquistados em árduas lutas. Esse era o sentido do discurso oficial.

Posto isso, surgem diversas questões: Qual foi a importância da guerra na conjuntura interna? De que forma o contexto de guerra foi utilizado pelo governo? Quais foram os primeiros impactos da guerra? O que mudou na economia? Como os trabalhadores reagiram às mudanças? Como as leis trabalhistas foram elaboradas e que decretos eram os que as flexibilizavam?

O período que chamamos do Estado Novo, 1937-1945, foi marcado, internamente, pelo crescimento industrial, pela instituição da Justiça do Trabalho, pela elaboração de leis sociais e trabalhistas, pela proibição de greves e pelo aumento do custo de vida. No âmbito externo, foram firmados contratos comerciais com a Inglaterra, a Alemanha e os Estados Unidos.

A aproximação do Brasil com Alemanha - Eixo, e Estados Unidos - Aliados, durante a guerra, não foi linear. Existiam disputas internas pela escolha que o governo brasileiro deveria seguir no conflito bélico. De um lado, estavam Oswaldo Aranha ${ }^{4}$ e Sousa Costa,${ }^{5}$ defendendo a aproximação com os Aliados; do outro, Filinto Muller intercedendo pelo Eixo. De acordo com Francisco Corsi, até 1942, tais disputas eram veladas, porém, após 1942, “começaram a aparecer as primeiras

3 Aliados: União Soviética, Estados Unidos, Império Britânico, China e França. Eixo: Alemanha, Itália e Japão.

4 Nomeado Ministro das Relações Exteriores, durante o Estado Novo.

5 Ministro da Fazenda de 1934 a 1945. Além disso, foi chefe da missão econômica enviada aos Estados Unidos no início de 1942, a qual resultou na assinatura dos Acordos de Washington. 
fissuras no edifício do Estado Novo", 6 o que acabou culminando em uma crise ministerial em julho de 1942.

As manifestações populares contra o Eixo se tornaram comuns. A exemplo disso, tem-se, após o naufrágio do navio brasileiro Cairu, em março de 1942, nas cidades de Porto Alegre e São Leopoldo, manifestações populares. O monumento aos imigrantes, localizado na Praça Centenário, em São Leopoldo, foi mutilado e, pouco mais de um mês depois do ocorrido, a praça teve seu nome modificado para Praça Tiradentes. ${ }^{7}$

Em agosto de 1942, as notícias dos naufrágios dos cinco navios brasileiros, por um submarino alemão, resultaram em ondas de "quebra-quebra" nas cidades gaúchas, como Pelotas, Santa Maria, Porto Alegre. A população, enfurecida, tomou as ruas em passeata, quebrando os bens dos imigrantes alemães e italianos. ${ }^{8} \mathrm{Em} 22$ de agosto, o governo decretou estado de beligerância e, no dia 31 do mesmo mês, estado de guerra contra as nações agressoras, exceto o Japão. ${ }^{9}$

Tanto os Aliados quanto o Eixo tinham interesse que o Brasil entrasse na guerra. Diante dessa situação, Vargas aproveitou a oportunidade para obter recursos que viabilizassem a construção da Siderúrgica de Volta Redonda, em troca de apoio na guerra. Com os alemães, manteve discussões para o financiamento da obra, mas

6 CORSI, Francisco L. Os rumos da economia brasileira no final do Estado Novo. 1991. Dissertação (Mestrado em Economia) - Instituto de Economia, Universidade Estadual de Campinas, Campinas, 1991. p.42.

7 SOARES, Tamires Xavier. Lei para todos: tensões trabalhistas entre "súditos do Eixo" e empregadores, durante a Segunda Guerra Mundial, em Pelotas. 2016. Dissertação (Mestrado em História) - Pontifícia Universidade Católica do Rio Grande do Sul, Porto Alegre, 2016. p. 75.

8 Para mais, ler: FACHEL, José $P$. As violências contra os alemães e seus descendentes, durante a Segunda Guerra Mundial, em Pelotas e São Lourenço do Sul. 2002. Tese (Doutorado em História) - Instituto de Ciências Humanas, Pontifícia Universidade Católica do Rio Grande do Sul, Porto Alegre, 2002; DALMOLIN, Cátia. Em nome da Pátria: as manifestações contra o Eixo em Santa Maria, no dia 18 de agosto de 1942. 2006. Dissertação (Mestrado em História) - Instituto de Filosofia e Ciências Humanas, Universidade de Passo Fundo, Passo Fundo-RS, 2006.

9 Os ataques a navios brasileiros, durante a guerra, foram efetuados por alemães e italianos, não havendo participação japonesa. Embora pouco abordado nas pesquisas, a Itália naufragou três navios brasileiros durante a guerra. $O$ primeiro a ir a pique foi o navio cargueiro Cabedelo; não há informações específicas a respeito do dia e o local em que o cargueiro naufragou. Acredita-se que tenha ocorrido entre os dias 14 e 25 de fevereiro de 1942, em algum lugar a leste das Antilhas Menores. Os outros dois navios naufragados por submarinos italianos foram: o cargueiro Comandante Lira, no dia 18 de maio de 1942, e o também cargueiro Afonso Pena, em 2 de março de 1943, ambos estavam em águas brasileiras. Desta forma, a declaração de guerra apresentada pelo Brasil, em 22 de agosto de 1942, foi direcionada à Alemanha e à Itália, países que estavam envolvidos nos naufrágios. A declaração de guerra ao Japão somente foi feita no dia 6 de junho de 1945. Para mais detalhes sobre a declaração brasileira de guerra ao Japão, ler KOIFMAN, Fábio; ODA, Humberto. A declaração brasileira de guerra ao Japão. In: XXVII SIMPÓSIO NACIONAL DE HISTÓRIA, 2013. Natal. Anais [...]. Natal: ANPUH 2013. p. 1-16. 
as batalhas travadas no oceano Atlântico e a distância da Alemanha dificultavam o contato, haja vista que os cabos de telégrafos que ligavam América com a Alemanha foram cortados pela Inglaterra em 1939. Ademais, o bloqueio britânico tornava inviável o transporte dos materiais necessários para tal construção. ${ }^{10}$

Utilizando-se da neutralidade durante boa parte do período que perdurou a guerra, o governo brasileiro, ao mesmo tempo em que negociava com a Alemanha, também fazia tentativas de convênios com os Estados Unidos. Segundo Alexandre Fortes, antes da década de 1940, "diversos gestores da política econômica brasileira cumpriram a rotina de peregrinar em vão a Washington", com o intuito de celebrar acordos comerciais que aumentassem as "exportações para os EUA" e ao mesmo tempo garantissem o "ingresso de dólares necessários às importações do país e à realização de investimentos capazes de alavancar o seu desenvolvimento industrial", no entanto, não obtinham sucesso em suas propostas. Porém, entre 1940 e 1942, por meio da análise empírica em documentações dos consulados, percebeu-se o que se chama de "súbita disposição dos Estados Unidos em finalmente conceder ao Brasil o status de aliado estratégico". Para ilustrar isso, tem-se o apoio financeiro e técnico para a construção da Siderurgia Estatal de Volta Redonda, que os vizinhos da América se disponibilizaram a fornecer.

A conjuntura mundial foi bastante utilizada como argumento para continuidades e rupturas dentro do regime estadonovista. De acordo com Pedro Dutra Fonseca, "grande parte do êxito do regime do Estado Novo na economia e na política deve ser atribuído ao contexto de guerra". ${ }^{11}$ Após o plano Cohen, ${ }^{12}$ a justificativa para Vargas se manter no poder era a guerra, artigo 175, da Constituição de 1937, que previa o seguinte:

O primeiro período presidencial começará na data desta Constituição. $O$ atual Presidente da República tem renovado o seu mandato até a realização do plebiscito a que se refere o art. 187, terminando o período presidencial fixado no art. 80 , se o resultado do plebiscito for favorável à Constituição. ${ }^{13}$

10 FORTES. op. cit., 2014. p. 7.

11 FONSECA, Pedro Cezar Dutra. Vargas: o capitalismo em construção 1906-1954. São Paulo: Hucitec, 2014. p. 281.

12 O Plano Cohen foi um documento redigido pelo integralista Olímpio Mourão, em 1937, com o devido conhecimento de Getúlio Vargas, com a intenção de simular a intenção de uma revolução comunista no Brasil, o que justificou o cancelamento das eleições de 1938, bem como o estado de sítio.

13 BRASIL. [Constituição (1937)]. Constituição dos Estados Unidos do Brasil. art. 175. Disponível em: http://www.planalto.gov.br/ccivil_03/constituicao/constituicao37.htm. Acesso em: 25nov. 2017. 
O artigo 187 assegurava que a Constituição entraria em vigor e seria submetida ao plebiscito nacional em 1943, conforme determinação do artigo 80, o qual estipulava o prazo de seis anos de mandato para o presidente, bem como a vigência da carta de 1937. No entanto, juntamente com a declaração de guerra, o governo brasileiro lançou, em 31 de agosto de 1942, o Decreto-lei 10.358, ${ }^{14}$ que suspendia seis artigos da Constituição, dentre eles o artigo 175, ou seja, tal decreto prorrogava o prazo estabelecido para a duração do mandato.

Entretanto, a posição brasileira, ao lado dos Aliados, na Segunda Guerra Mundial, deixava margens para uma grande contradição, pois um regime autoritário, como o de Vargas, estava saindo em defesa de países democráticos, mandando seu povo para o front, na Itália, para lutar contra um governo ditatorial e fascista, como era o de Mussolini. As mobilizações populares, que antes demandavam que o Brasil apoiasse os Aliados, a partir da declaração de guerra, "desdobraram-se em movimentos de contestação à ditadura". ${ }^{15}$ Todavia, era empregado como argumento a necessidade de um país unido em favor de uma luta contra o Eixo e de colaboração mútua.

No aspecto econômico, o café, após a crise de 1929, deixou de ocupar o carrochefe da economia brasileira, mas sua produção não havia declinado até a Segunda Guerra Mundial. Após o golpe do Estado Novo, Vargas "decidiu aliviar o ônus que a sustentação do café acarretava para o governo, bem como atender aos reclamos dos cafeicultores, reorientando a política cafeeira para a liberdade de mercado". Essa atitude resultou no crescimento das exportações e na queda do preço do produto. Apesar disso, a guerra provocou "refluxo" no comércio internacional do café: "em 1940, os Estados Unidos firmaram um acordo com 14 países produtores, estabelecendo quotas de importação e fixando um preço-teto" ${ }^{16}$ que seria modificado somente em 1943, quando os vizinhos norte-americanos, após a definição do cenário do conflito favorável aos aliados, "passaram a se mostrar menos generosos e flexíveis"17 conosco.

Além de desonerar os cofres públicos dos gastos pela sustentação da produção de café, a industrialização do país também era um dos objetivos do governo

14 BRASIL. Decreto-lei 10.358, de 31 de agosto de 1942. Disponível em: http://www.planalto.gov.br/ccivil_03/decreto/1930-1949/D10358.htm\#art2. Acesso em: 25nov.2017.

15 CORSI, op. cit., p. 38.

16 LEOPOLDI, Maria Antonieta. Estratégias de ação empresarial em conjunturas de mudança política. In: PANDOLFI, Dulce. Repensando o Estado Novo. Rio de Janeiro: FGV, 1999. p. 121.

17 FORTES, op. cit., 2014. p. 7. 
provisório. Conforme a tabela apresentada por Maria Leopoldi, a industrialização cresceu $125 \%$ na década de 1930 e teve uma pequena queda com o início da guerra. Todavia, em 1942, voltou a crescer.

\section{Tabela 1}

Taxa de crescimento anual da produção agrícola e industrial brasileira - 1920/39

\begin{tabular}{cc|c|c}
\hline & $\mathbf{1 9 2 0 - 2 9}$ & $\mathbf{1 9 2 9 - 3 3}$ & $\mathbf{1 9 3 3 - 3 9}$ \\
\hline Produção agrícola & 4,1 & 2,4 & 2,0 \\
\hline Produção industrial & 2,8 & 1,3 & 11,3 \\
\hline
\end{tabular}

Fonte: Leopoldi e colaboradores (op. cit., p. 122).

A tabela elaborada por Leopoldi demonstra não só o declínio que a industrialização sentiu, com o início do confronto mundial e sua recuperação, mas também aponta para uma diminuição de mais de $50 \%$ da produção agrícola, entre os anos de 1920 e 1939, e o crescimento da indústria, entre 1933 a 1939, o que estava ligado aos grandes incentivos do governo, como, por exemplo, o Plano Especial de Obras Públicas, em que "os gastos com a defesa, infraestrutura e indústria de base perfaziam cerca de $90 \%$ dos gastos totais do plano, enquanto que os gastos sociais giravam em torno de $3,5 \% "{ }^{18}$

Apesar do crescimento da industrialização, o Brasil ainda dependia muito das importações, as quais foram gravemente afetadas com a eclosão da guerra em 1939. Empresas de transporte público, como a Carris de Porto Alegre, reduziram seus horários de bonde para evitar o excessivo desgaste das peças, já que havia grande dificuldade de consegui-las por serem importadas. Para Francisco Corsi e Maria Antonieta Leopoldi, é possível dividir a economia, durante o período beligerante, em dois momentos: o primeiro vai de 1939-1942, sendo marcado pela estagnação; e o segundo, de 1943-1945, quando houve um considerável crescimento da industrialização, como se pôde notar na tabela apresentada anteriormente.

O crescimento percebido entre 1943 e 1945 não solucionou um dos grandes problemas para economia brasileira durante a guerra: a grande inflação. De acordo com Corsi, os preços por atacado, entre $1942 / 1945$, subiram $84 \%{ }^{19}$. Como solução para essa questão, o governo passou a criar medidas para diminuir a liquidez. Entre essas, estavam a taxação de lucros extraordinários e o pagamento de obrigações de guerra, que previa aos empregadores o recolhimento de forma compulsória "mês a

18 CORSI, op. cit., p. 47.

19 CORSI, op. cit., p. 82.

Revista Mundos do Trabalho | Florianópolis | vol. 11 | 2019 | p. 1-14 
mês, nos institutos e caixas de aposentadoria e pensões respectivos, de importância igual a três por cento do montante dos salários ou ordenados ou comissões que tiverem de pagar aos associados desses institutos". Ressalta-se que os funcionários públicos e os extranumerários também estavam sujeitos ao mesmo desconto. ${ }^{20}$

Conforme pesquisa realizada pela Secção de Estudos Econômicos e Financeiros, em 1944, apresentado em forma de relatório ao presidente, a grande inflação era gerada pelos empenhos intensos do governo, desde 1939, em construir empreendimentos que não traziam respostas imediatas para o consumo, como, por exemplo, a Siderúrgica do Vale do Rio Doce e a Fábrica de Motores, "cuja importância econômica é indiscutível, mas que só produzirão uma expansão de bens de consumo no futuro". O relatório também afirmava que as convocações para guerra, bem como o "desenvolvimento que se verifica nos centros urbanos - obras de embelezamento e construção de edifícios", ${ }^{21}$ estavam contribuindo para "desviar os braços da lavoura" e, como consequência disso, faltavam alimentos nos comércios das cidades brasileiras.

Algumas medidas foram apontadas para conter a inflação, a saber:

a) Convidar o Instituto e a Comp. de Seguros a adquirirem, no mercado, títulos do Governo e títulos da dívida externa;

b) Com a elevação da cotação dos títulos do Governo no mercado, lançar a $2^{\underline{a}}$ série das Obrigações de Guerra;

c) Vender as Letras do Tesouro aos Bancos, em grande escala;

d) Consolidar as emissões de papel moedas já realizadas, sobre as Letras do Tesouro, criando a Superintendência da Moeda e do Crédito com a faculdade de emitir sobre ouro;

e) Reproduzir as facilidades de emissões para as Letras do Tesouro;

f) Facilitar a emissão para títulos relativos a certos produtos agrícolas, ligados à alimentação;

h) Exercer sistematicamente a fiscalização das Carteiras dos Bancos;

i) Instituir um sistema de regulamentação de transporte rodoviário de modo a limitar, algumas vezes por semana, o transporte de artigos que não os de alimentação;

j) Efetivar as facilidades prometidas para a construção de armazéns ou sua utilização para guarda de cereais;

20 BRASIL. Decreto-lei 4.789 de outubro de 1942, Art. 6 e 7. Disponível em: http://www.planalto.gov.br/ccivil_03/decreto-lei/1937-1946/Del4789.htm. Acesso em: 29 nov. 2017.

21 BRASIL. Ministério da Fazenda. Secção de Estudos Econômicos e Financeiros. Situação financeira brasileira em virtude do estado de guerra, 1944. Rio de Janeiro: FGV, CPDOC, 1944. Trata-se de fundo do Ministério da Fazenda, classificação: SC, mf, dg, 1944.10.14. 
k) Instituir subsídios em determinados casos, de fácil exequibilidade e de ampla repercussão, como os subsídios de frete;

I) Desenvolver a formação dos "Depósitos de Garantia" e da "compra de Certificados de Equipamentos" mediante elevação das taxas de importo sobre lucros extraordinários e redução da margem entre o lavor do imposto e a obrigatoriedade do depósito;

m) Promover a prioridade de importação de máquinas obtidas com os certificados de Equipamento e do material de transporte;

n) Em geral, para o ano de 1945, proibir todas as novas obras federais, estaduais ou municipais e aumentar as facilidades de crédito e de compras nas regiões rurais e dificultar os créditos nos centros urbanos. $^{22}$

Por fim, a Secção de Estudos Econômicos e Financeiros afirmava que se o governo optasse por continuar disponibilizando créditos a particulares e prosseguisse com o programa de obras, a situação iria se agravar de tal forma que ficaria "caótica e impossível de controlar". ${ }^{23}$ Porém, nem todas as recomendações foram seguidas por Vargas. Por intermédio da leitura de bibliografias e de pesquisas de decretos-lei, pode-se identificar que apenas as letras, A, C, D, L ${ }^{24}$ foram consideradas pelo então presidente.

Com olhares contemporâneos sobre o período da guerra, hoje se acredita que não foram os investimentos em obras públicas e em empresas estatais os responsáveis pela inflação e pela escassez de trabalhadores no campo. É necessário lembrar que a industrialização brasileira, até 1930, estava em estágio embrionário, portanto, durante a Segunda Guerra, o Brasil ainda dependia das importações, não havia um parque industrial fortalecido, nem mesmo empresas de base. Desse modo, acredita-se que a inflação enfrentada pelos brasileiros, durante o período em questão, foi fruto de um país despreparado, com uma economia em transição. Alexandre Fortes afirma que o acordo assinados entre os Estados Unidos e o Brasil "contribuiu decisivamente para a superação do impacto inicialmente desorganizador da guerra sobre a economia brasileira, que se refletia na combinação entre inflação, recessão e escassez de divisas que perdurou até1942", haja vista que "a partir daí o ajuste gerado pelo suprimento às demandas de guerra contribuiu para o crescimento e para a retomada das exportações".${ }^{25}$ Contudo, a

\footnotetext{
BRASIL. Ministério da Fazenda, op. cit., p. 6, 7 e 8.

Ibidem, p. 9.

4 BRASIL. Decreto-lei 7.293 de, 02 de fevereiro de 1945. Disponível em: http://www.planalto.gov.br/ccivil_03/Decreto-Lei/1937-1946/Del7293.htm. Acesso em: 29 nov. 2017.

25 FORTES, op. cit., 2014. p. 7
}

Revista Mundos do Trabalho | Florianópolis | vol. 11 | 2019 | p. 1-14 
situação não foi solucionada, o acordo apenas amenizou os profundos problemas econômicos enfrentados pelo país.

Com o intuito de se compreender melhor a questão da economia agropastoril no Rio Grande do Sul, foi analisado o jornal Correio do Povo, durante os oito meses anteriores à eclosão da guerra, à procura de notícias sobre gêneros agrícolas e pecuários. Nessa análise, notou-se que existiam muitas incidências de notícias sobre problemas com os seguintes produtos: gado/carne, trigo, leite, lã, banha, fumo e açúcar. O levantamento de janeiro a agosto de 1939 está representado no gráfico a seguir.

\section{Figura 1}

Incidência de notícias sobre abastecimento.

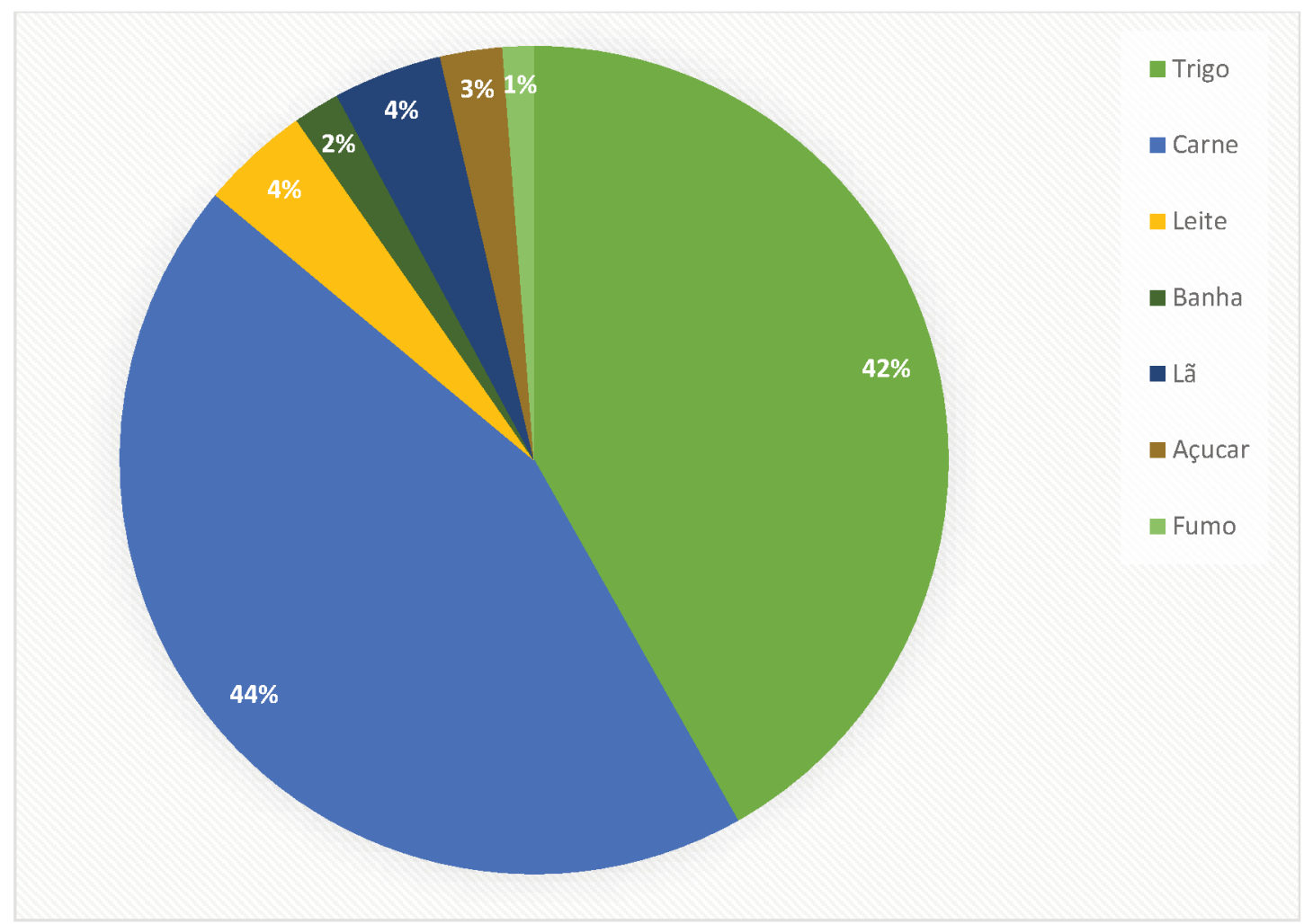

Fonte: Correio do Povo (jan.-ago. 1939)

Ao total, foram compiladas 165 notícias; dessas, 44\% tratavam sobre o problema do abastecimento de gado/carne e $42 \%$, do trigo, mostrando, portanto, que, embora o estado do Rio Grande do Sul fosse grande produtor de gado de corte, havia necessidade de incrementar a produção, ainda que com cautela.

Em matéria no jornal Correio do Povo, o autor ${ }^{26}$ afirmou que a guerra possibilitava várias oportunidades para o mercado de produtos agrícolas brasileiros, já que "é esse barbarismo infernal que abre, de momento, todas as portas à

26 A publicação não foi assinada por ninguém, algo bastante comum no jornal analisado. 
colocação dos variados produtos de nossa lavoura e de nossa pecuária". Porém, ressaltava que era necessário ter cautela, pois essa brecha era momentânea e deveria considerar que "após a guerra a crise será fatal e tanto maior quanto mais prolongada e mais extensa for aquela". Esses avisos muitas vezes vinham relembrando a situação causada pela Primeira Guerra Mundial, que incitou um breve momento de euforia econômica no mercado e, logo após, veio a crise devido à grande produção. Não é raro encontrar notícias sobre a economia e a produção agropastoril da Argentina e do Uruguai no periódico em questão. Para agregar seu argumento, o autor traduziu uma notícia do jornal La Mañana de Montevideo:

\begin{abstract}
No conflito de 1914-1918, foram muitos os que acreditaram que os anos de preços altos de rezes caras, fossem gordas ou magras, não iam terminar, e estenderam seus negócios não somente até onde permitiam as grandes estradas do momento, mas também até as possibilidades extremas do crédito generoso nas horas de inflação. Quando cessou a guerra, e não se venderam as remessas extraordinárias que haviam continuado imprudentemente seu ritmo excepcional, a liquidação resultou ruinosa, arrastando as utilidades e lucros recentes e não raro o próprio capital inicial, que nunca seria comprometido se a prudência houvesse inspirado o compromisso de negócios, em todos os ramos da produção que, então, se valorizara. Esta situação perturbou até em suas mais fundas raízes a economia da República. ${ }^{27}$
\end{abstract}

Considerando a conjuntura, o orçamento para o ano de 1942 previa "vultosas verbas para auxiliar a pecuária e a agricultura do país"28, que foram recebidas por diversos órgãos, como a Inspetoria do Fomento da Produção Animal de Bagé, e resultaram em campos de sementes de cereais e leguminosas em São Borja e Estação experimental de trigo de Passo Fundo. Em declaração ao Correio do Povo ${ }^{29}$ Alcides Marques, vice-presidente da FARSUL, ${ }^{30}$ declarou que a safra a começar no mês de fevereiro seria menor do que a passada, visto que o gado em geral não estava "suficientemente preparado devido a inclemência do inverno". Os preços haviam tido um considerável aumento, pois o mercado exterior mostrava-se agitado, o que levava a crer que seria uma safra lucrativa para criadores e industrializados de produtos pecuários.

No final de fevereiro, o Sindicato dos Invernistas e Criadores de Gado, com sede em Barretos, já anunciava a encomenda de 69 mil toneladas de carne, sendo grande parte destinada aos Estados Unidos e Inglaterra, cifras estas superiores a

27 Correio do Povo, Porto Alegre, 30 jun.1939. p. 10

28 Auxílio oficial a pecuária e a agricultura. Correio do Povo, Porto Alegre, 6 fev. 1942. p. 5.

29 A nova safra de gado. Correio do Povo, Porto Alegre, 13 fev. 1942. p. 5.

30 Federação da Agricultura do Estado do Rio Grande do Sul. 
toda a produção de exportação de conservas em 1941. ${ }^{31}$ Diante disso, o governo brasileiro lançou um decreto que limitava a matança de vacas e terneiros com o intuito de impedir a diminuição dos rebanhos nacionais. Os pecuaristas colocaramse contra essa medida considerada sem fundamento, argumentavam que para garantir a manutenção dos rebanhos bastava diminuir a mortalidade dos animais por meio do combate a sarna, tuberculose, raiva, aborto epizoótico, carbúnculo e carrapato. $^{32}$

A carne, juntamente com o arroz e o feijão, era a base do prato da classe trabalhadora gaúcha; sendo assim, o aumento do preço da carne bovina refletiu diretamente no custo de vida das famílias. Para amenizar a carestia dos gêneros de primeira necessidade, os valores de alguns cortes, chamados de populares, foram tabelados pelo governo. A respeito, em sua tese, Nauber Silva afirmou que:

Desde a década de 1940 o problema de racionamento de carne de gado esteve presente na cidade de Porto Alegre, sendo debatida pelas lideranças operárias como um tema significativamente sensível. Uma publicação econômica do Estado dedicava algumas notas sobre a 'luta' dos produtores para alinhar o preço do mercado mundial, enquanto consumidores gaúchos demandavam preços menores. ${ }^{33}$

A procura de carne verde, charque, banha e outros derivados, era intensa, o que ocasionava, conforme a lei da oferta e da procura, a majoração dos preços. Diante desse problema, o prefeito de Porto Alegre, Loureiro da Silva, criou a Comissão de Tabelamento da Carne Verde, alegando que "só a organização de uma comissão de interessados diretos no assunto poderia resolver a questão da carne". Não foram raras as vezes em que o preço do gado vacum sofreu alterações e a população reclamava da nova dieta, exigindo das autoridades providências a respeito do alto custo de vida.

As implicações na questão alimentar podem ser percebidas até mesmo nos cadernos de receitas, em um livro produzido pela marca Royal, em 1940, denominado Economia Culinária, onde eram apresentadas receitas de pratos que utilizavam sobras de alimentos, sem deixar que houvesse desperdícios. Uma das receitas que nos chamou atenção foi a de Pudim de Galinha, cuja introdução trazia a seguinte explicação: "Os homens em geral preferem pratos fortes e as senhoras iguarias

31 O problema de exportação de carne em face da guerra. Correio do Povo, Porto Alegre, 21 fev. 1942. p. 5.

32 A restrição na matança de vacas e terneiros. Correio do Povo, Porto Alegre, 27 fev. 1942. p. 2.

33 SILVA, Nauber. $O$ "mínimo" em disputa: salário mínimo, política, alimentação e gênero na cidade de Porto Alegre (c. 1940 - c. 1968). 2014. Tese (Doutorado em História) - Instituto de Ciências Humanas, Universidade Federal do Rio Grande do Sul, Porto Alegre, 2014. 
delicadas e originais. Esta receita satisfaz a todos. É o melhor meio que conheço de utilizar sobras de galinha". ${ }^{34} \mathrm{O}$ consumo de frango não era comum aos trabalhadores, tendo em vista seu alto valor, mas com o aumento do preço da carne de boi e sua escassez no mercado, mostrava-se como uma alternativa para o problema.

Embora tenham sido elaboradas diversas medidas para controlar a produção, a exportação e o consumo de carne, o produto faltava nos açougues. Além disso, o custo de vida do trabalhador brasileiro estava muito alto, o salário não era suficiente para cobrir as despesas mensais e havia casos de trabalhadores que acabavam furtando alimentos em seus empregos, como o caso de Elsa Winter Bischoff, uma viúva que trabalhava na Sociedade de Açougues Ltda., ${ }^{35}$ que acabou sendo demitida por cometer furtos dessa natureza, não recebendo aviso prévio, férias, nem indenização por ser dispensada sem justa causa.

A empresa acusou a senhora de roubo, comentando que ela "usava uma caixinha, toda especial, em cujo conteúdo costumava depositar papéis servidos, para nela também ocultar várias mercadorias", tais como "sanduíches, charques, salames, linguiças" e, ao levar a dita caixinha até o lixo, para desfazer-se dos papéis, acabava escondendo os produtos desviados.

A primeira Junta de Conciliação e de Julgamento de Porto Alegre entendeu que havia provas dos supostos desvios e, por isso, a demissão era justificada, mas as férias eram de direito da trabalhadora, portanto, julgou procedente, em parte, condenando a empresa a pagar o período de férias em dobro. A leitura dos autos não deixa explícito se o que Elsa escondia na dita caixa eram restos deixados pelos clientes ou produtos novos, mas sinaliza para as dificuldades passadas pela população durante esse período de carestia e de escassez.

\section{Conclusão}

O período da guerra, conforme se pode notar neste artigo, ocasionou diversos percalços, tais como escassez de alimentos, de borracha, combustível, mas também muitos lucros para os empresários, os quais vislumbraram uma oportunidade para aumentar sua produção e elevar os preços dos produtos.

O Rio Grande do Sul era conhecido por seus rebanhos de gado vacum; ademais, vários frigoríficos, como Armur, Swift e Anglo, tinham suas sedes no estado. Mesmo assim, os trabalhadores gaúchos conheceram a escassez do alimento base da sua

34 SILVEIRA, Maria. Economia culinária. Rio de Janeiro: Off Graphic Mauá, 1940. p.2.

35 Revista O Orientador: Trabalho Indústria e Comércio, Porto Alegre, 16 de novembro de 1942, n. 32, p. 1635. 
dieta, a carne verde. De imediato, os governantes locais estabeleceram tabelamento dos preços para conter seu exacerbado aumento, implantando cortes populares, que deveriam ser vendidos a baixo custo; paralelamente, fiscais visitavam os estabelecimentos para garantir o controle. Em caso de constatação de desobediência ao tabelamento ou até mesmo de fraudes ${ }^{36}$, os responsáveis responderiam no Tribunal de Segurança Nacional por crime contra economia popular.

A análise mais detalhada desses documentos será realizada na tese de doutorado que está em fase de produção, mediante a leitura crítica das fontes aqui analisadas, onde pudemos constatar que havia, por parte das autoridades, uma crescente preocupação com o modo como conduzir a solução dos problemas econômicos que se apresentavam: de um lado, as empresas e produtores agropecuários pressionavam o governo para que intervisse de forma moderada nos assuntos econômicos; do outro a classe trabalhadora lutava para garantir sua sobrevivência diante de tantas faltas e majorações. O caso da trabalhadora Elsa elucida bem a necessidade que a maioria da população gaúcha passava naqueles anos de escassez, uma vez que a guerra travada do outro lado do oceano Atlântico chegara ao prato da camada menos favorecida de sociedade, que, além de ter de lutar pela garantia das leis trabalhistas, enfrentava severas mudanças em sua dieta alimentar.

Recebido em 05/10/2019

Aprovado em 22/11/2019

36 Não são raros os casos de balanças adulteradas. 